\title{
Drug-resistant tuberculosis control in South Africa: scientific advances and health system strengthening are complementary
}

\author{
Nesri Padayatchi BSc MBChB MSc, Marian Loveday BSc MPhil \& Naressa \\ Naidu BSc (Hons) MMed Sc
}

To cite this article: Nesri Padayatchi BSc MBChB MSc, Marian Loveday BSc MPhil \& Naressa Naidu BSc (Hons) MMed Sc (2014) Drug-resistant tuberculosis control in South Africa: scientific advances and health system strengthening are complementary, Expert Opinion on Pharmacotherapy, 15:15, 2113-2116, DOI: 10.1517/14656566.2014.953053

To link to this article: http://dx.doi.org/10.1517/14656566.2014.953053

曲 Published online: 16 Sep 2014.

Submit your article to this journal $₫$

Џلll Article views: 329

Q View related articles $\longleftarrow$

View Crossmark data $\nearrow$ 


\section{EXPERT
OPINION \\ EXPERT
OPINION}

\section{informa} healthcare

\section{Drug-resistant tuberculosis control in South Africa: scientific advances and health system strengthening are complementary}

\author{
Nesri Padayatchi ${ }^{\dagger}$, Marian Loveday \& Naressa Naidu \\ ${ }^{\dagger}$ University of KwaZulu-Natal, Nelson R. Mandela School of Medicine, Centre for the AIDS \\ Programme of Research in South Africa, Durban, South Africa
}

We examine some aspects of the South African health system that have contributed to the current multi- and extensively drug-resistant tuberculosis $(\mathrm{M}(\mathrm{X}) \mathrm{DR}-\mathrm{TB})$ epidemic and identify opportunities for change and improvement. Implementation of several recent major scientific advances have the potential to accelerate the control of $M(X) D R-T B$, but health systems strengthening will be essential.

\begin{abstract}
Keywords: extensively drug-resistant tuberculosis, health systems strengthening, multi-drug-resistant tuberculosis
\end{abstract}

Expert Opin. Pharmacother. (2014) 15(15):2113-2116

Decades of sub-standard, poorly implemented tuberculosis (TB) control programme guidelines and interrupted TB treatment, combined with neglect in drug development, has seen the emergence of both multi- and extensively-drug resistant TB $[M(X) D R-T B][1]-a$ public health crisis of particular concern in South Africa where both TB and HIV epidemics have converged. Therapeutic options for drugresistant TB are limited by efficacy, acceptability, availability, tolerability and financial constraints. Since 2006, the number of M(X)DR-TB cases in South Africa has increased temporally [2] and in 2013 the WHO identified South Africa as having the second-highest number of MDR-TB cases worldwide [3]. Since the prevalence of drug-resistant $\mathrm{TB}$ is considered a measure of the effectiveness of existing TB control programmes [4], these statistics emphasise grave inadequacies in current treatment and management strategies for TB in South Africa and highlight an ailing health system. Here, we examine aspects of the South African public health system which have contributed to the current situation and evaluate the role of scientific advances in the control of drug-resistant TB.

The treatment of $\mathrm{M}(\mathrm{X}) \mathrm{DR}-\mathrm{TB}$ is protracted, toxic, resource-intensive [5] and plagued by poor patient adherence [6]. South African data for the period $2000-$ 2004 show that standardised treatment for MDR-TB resulted in an overall treatment success rate of only 46\% [7]. The mortality rate in HIV-infected patients was $35.2 \%$, more than double than in HIV-negative patients [7]. Treatment success rates are considerably lower in XDR-TB, an ominous threat to gains made in HIVTB programmes. A 24-month study of XDR-TB in South Africa in which $73 \%$ of the cohort was HIV co-infected, but only $61 \%$ received combined anti-retroviral therapy (cART), reported a treatment success rate of just $22 \%[8]$. Since then there has been compelling scientific evidence demonstrating the role of concurrent second-line anti-TB chemotherapy and cART administration in improving sputum conversion rates and reducing mortality in M(X)DR-TB-HIV co-infected patients [8-10]. Encouragingly, the National Tuberculosis Programme responded and the South African ART guidelines were amended in 2010 to incorporate the 


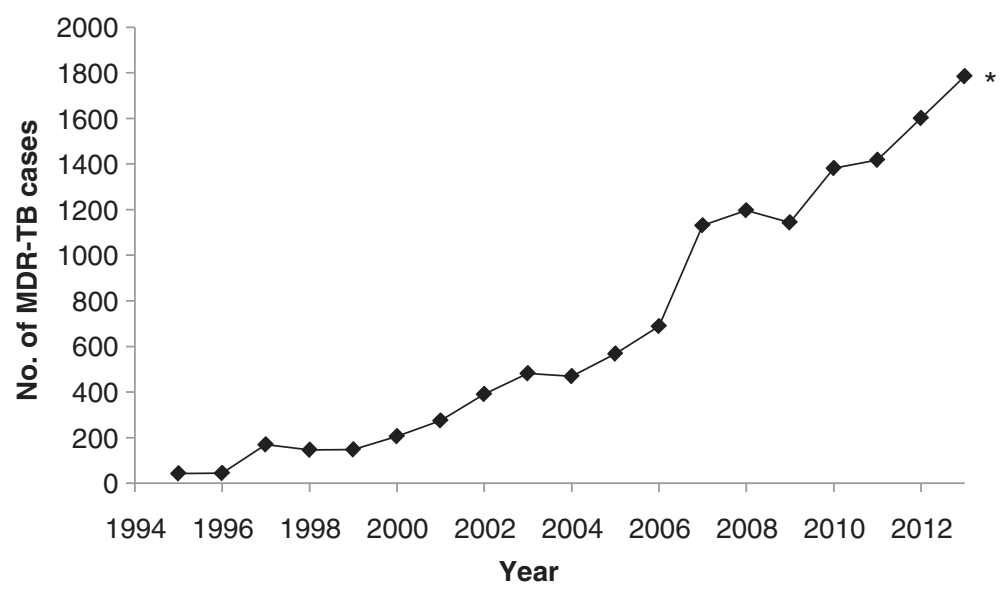

Figure 1. Data regarding the Number of MDR-TB cases initiated on treatment at a TB specialist hospital in South Africa between 1995 and 2013.

Estimated figure is based on data available for the first three quarters of 2013.

MDR-TB: Multi-drug-resistant tuberculosis.

recommendation that TB-HIV co-infected patients be initiated on cART irrespective of the CD 4 cell count. Three years on, data from the third quarter of 2013, at one of the largest TB drug-resistant treatment facilities in South Africa, show that $19 \%$ of MDR-TB-HIV co-infected patients were not initiated on cART.

There is some evidence that operational challenges in implementing the current guidelines and the sub-optimal use of existing drugs contribute to low treatment success rates [11]. Such operational challenges occur at various levels of the health system. A recent study describes the treatment journey of a typical patient, and highlights numerous flaws within a health system that ultimately fails its dependants [12]. A 6-week time lag for notification of culture results; a month's delay in hospital admission due to limited inpatient capacity; incomplete treatment regimens as a result of drug stock-outs and delayed cART initiation (attributable to poor integration of TB and HIV services) have since informally been accepted as 'standard of care'. Alarmingly, recent data, from another province in South Africa, show that only 63\% of newly diagnosed MDR-TB patients initiated treatment in 2011 [13]. Further, a random chart review of 186 patients referred to a centralised MDR-TB facility in KwaZulu-Natal in 2010 show that only $25 \%$ were initiated on treatment within 8 weeks, leaving $75 \%$ of patients experiencing a mean delay of 12.36 weeks (in addition to the $6-8$ weeks required for culture and susceptibility testing) [14]. Such issues, in conjunction with patient-related socioeconomic problems make the Millennium Development Goal of eradicating TB by 2050 elusive in this resource-poor setting.

Novel anti-TB agents such as bedaquiline and delamanid and re-purposed drugs such as linezolid, significantly shortened treatment programmes such as the 'Bangladesh Regimen' [11] and innovative point-of-care diagnostics such as
Xpert MTB/RIF ${ }^{\circledR}$ personify the scientific advances considered essential in regaining control of drug-resistant $\mathrm{TB}$ but the question remains whether they can have the desired impact on their own.

The advent of Xpert MTB/RIF has since substantially reduced the time to MDR-TB treatment initiation by approximately two-thirds at some sites in South Africa (Dr Iqbal Master, personal communication, October 2013); however, its ability to provide a diagnosis within a few hours suggests that this delay could, in theory, be further reduced. Xpert MTB/RIF has also paradoxically further intensified the burden, increasing MDR-TB case detection resulting in an escalation in the number MDR-TB cases initiated on treatment (Figure 1) and an unwavering patient admission waiting list (Figure 2). Figure 2 illustrates the number of patients with $\mathrm{M}(\mathrm{X}) \mathrm{DR}-\mathrm{TB}$ awaiting admission at a TB specialist hospital with a maximum capacity of 192 beds, over a 7-year period. Although fluctuating, the numbers remain unacceptably high and reveal a lack of intervention to ensure a sustained decline in waiting time, despite this facility initiating treatment in $65 \%$ of patients in outpatient care. The limited inpatient capacity has other important public health implications. Pietersen $e t$ al. found that $42 \%$ of patients with XDR-TB who were discharged had failed treatment [15]. Further, these patients had a median survival time of 19.84 months from the time of discharge. These data reveal a critical gap in current TB control programmes where potential disease transmission requires urgent interruption.

Unlike scientific advances, TB control programmes appear to have stagnated. These factors demonstrate a health system unable to exploit the potential of available resources. Cumulatively, they are an ominous threat to drug-resistant TB control, exacerbating patient-related socioeconomic problems, 


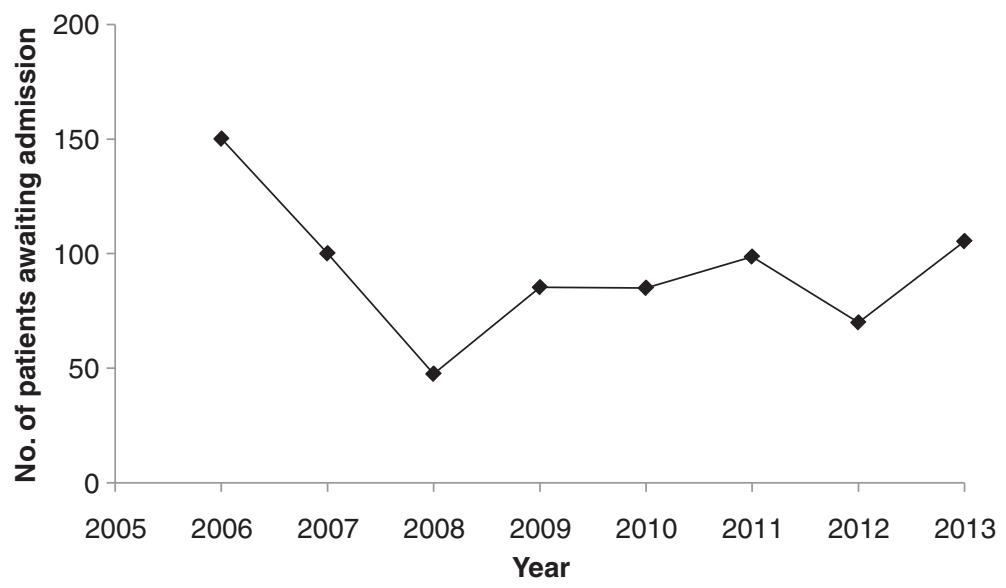

Figure 2. Data regarding the number of patients awaiting treatment initiation and admission at a TB specialist hospital in South Africa between 2006 and 2013.

TB: Tuberculosis.

fuelling transmission in vulnerable communities, urgently requiring strategic intervention.

\section{Expert opinion}

Major developments in drug availability, shortened, bettertolerated treatment regimens and innovative diagnostic tools have the potential to vastly enhance current programmes and accelerate the control of $\mathrm{M}(\mathrm{X}) \mathrm{DR}-\mathrm{TB}$. Although these advances highlight the way forward, they too will inevitably fail in a fragile health system. The burden of the M(X)DRTB has prompted a culture that strives towards quantity as opposed to quality of healthcare administered, often neglecting to implement even the most basic principles of care without capitalising on available tools. It is imperative that we do not underestimate the role and value of health systems'strengthening. We need to identify weaknesses and develop strategies that target such limitations. Stakeholder commitment to TB control, improved provider performance and enhanced morale in healthcare workers, combined with the necessary support and infrastructure, will be essential in containing the scourge of this disease. Unless these interventions complement each other, an unfortunate outcome is inevitable.

\section{Acknowledgments}

$\mathrm{N}$ Padayatchi is supported by the Centre for AIDS Programme of Research (CAPRISA). CAPRISA is funded by the NIH and the US Department of Health and Human Services (DHHS); grant No A1069469). Naressa Naidu and Marian Loveday are supported by the Columbia UniversitySouthern African Fogarty AIDS International Training and Research Program (AITRP), Implementation Science Traineeship Program funded by the United States President's Emergency Plan for AIDS Relief (PEPFAR) through the Fogarty International Center, National Institutes of Health (grant No 5 D43TW00231 S2).

\section{Declaration of interest}

The authors have no relevant affiliations or financial involvement with any organisation or entity with a financial interest in or financial conflict with the subject matter or materials discussed in the manuscript. This includes employment, consultancies, honoraria, stock ownership or options, expert testimony, grants or patents received or pending, or royalties. 


\section{N. Padayatchi et al.}

\section{Bibliography}

1. Global alliance for TB drug development. 2013. Available from: http://www. tballiance.org/why/mdr-xdr.php [Cited 25 June 2014]

2. Falzon D, van Gemert W, Glaziou P, et al. Management of drug-resistant tuberculosis: Policy Guidelines. National Department of Health, Republic of South Africa; 2013

3. WHO. Global tuberculosis report 2013. World Health Organization, Geneva Switzerland; Available from: http:// wwwwhoint/tb/publications/ global_report/en/2013

4. Weyer K, Lancaster J, Brand J, et al. Survey Of tuberculosis drug resistance in South Africa 2001 - 2002. Medical Research Council, Pretoria; 2004

5. Pooran A, Pieterson E, Davids M, et al. What is the cost of diagnosis and management of drug resistant tuberculosis in South Africa? PLoS One 2013;8(1):e54587

6. O'Donnell MR, Daftary A, Wolf A, et al. Adherence in the Treatment of Patients With Extensively Drug-Resistant Tuberculosis and HIV in South Africa: A Prospective Cohort Study. J Acquir Immune Defic Syndr 2014;67:22-9

7. Farley JE, Ram M, Pan W, et al. Outcomes of multi-drug resistant tuberculosis (MDR-TB) among a cohort of South African patients with high HIV prevalence. PLoS One 2011;6(7):e20436

8. O'Donnell MR, Padayatchi N,

Kvasnovsky C, et al. Treatment outcomes for extensively drug-resistant tuberculosis and HIV co-infection. Emerg Infect Dis 2013;19(3):416-24

9. Brust JC, Lygizos M, Chaiyachati K, et al. Culture conversion among HIV coinfected multidrug-resistant tuberculosis patients in Tugela Ferry, South Africa. PLoS One 2011;6(1):e15841

10. Padayatchi N. Outcomes of MDR-TB: new regimens, new drugs and more... FIDDSA. Drakensberg, South Africa; 2013. Available from: http://www.fidssa. co.za/B_Fidssa13Cong_Pres.asp

11. Van Deun A, Maug AK, Salim MA, et al. Short, highly effective, and inexpensive standardized treatment of multidrug-resistant tuberculosis. Am J Respir Crit Care Med 2010;182(5):684-92

12. Loveday M, Padayatchi N, Voce A, et al The treatment journey of a patient with multidrug-resistant tuberculosis in South Africa: is it patient-centred? Int J Tuberc Lung Dis 2013;17(10 Suppl 1):56-9

13. Ebonwu JI, Tint KS, Ihekweazu C. Low treatment initiation rates among multidrug-resistant tuberculosis patients in Gauteng, South Africa, 2011. Int J Tuberc Lung Dis 2013;17(8):1043-8
14. Narasimooloo R, Ross A. Delay in commencing treatment for MDR TB at a specialised TB treatment centre in KwaZulu-Natal. S Afr Med J 2012;102(6 Pt 2):360-2

15. Pietersen E, Ignatius E, Streicher EM, et al. Long-term outcomes of patients with extensively drug-resistant tuberculosis in South Africa: a cohort study. Lancet 2014;383(9924):1230-9

\section{Affiliation}

Nesri Padayatchi ${ }^{\dagger 1}$ BSc MBChB MSc, Marian Loveday ${ }^{2}$ BSc MPhil \& Naressa Naidu ${ }^{3}$ BSc (Hons) MMed Sc ${ }^{\dagger}$ Author for correspondence

${ }^{1}$ Deputy Director, University of KwaZulu-Natal, Nelson R. Mandela School of Medicine, Centre for AIDS Programme of Research in South Africa (CAPRISA), 2nd Floor, DDMRI,

719 Umbilo Road, Durban, 4013, South Africa Tel: +27 31260 4555;

Fax: +27 31260 4549;

E-mail: padayatchin@ukzn.ac.za

${ }^{2}$ Senior Scientist,

Health Systems Research Unit, Medical Research Council, Western Cape, South Africa

${ }^{3}$ Pre-Doctoral Fellow, Centre for AIDS

Programme of Research in South Africa (CAPRISA), 719 Umbilo Road, Durban 4013, South Africa 